\title{
El indígena y la tierra, en cuatro novelas recientes de Colombia
}

SE cree generalmente que el cinco por ciento de indígenas en la $\$$ población de Colombia, poco más o menos, no son suficientemente numerosos para servir de base a la literatura. Sin embargo, se ha escrito mucho sobre ellos, en todos los géneros literarios en ese país, desde los primeros años de la República hasta el período actual.

En Bolivia, Perú, Ecuador y otros países donde los indígenas forman una parte considerable de la población, existe el problema de la tierra. Se encuentra ese problema también en Colombia. No es aquí tan extenso, ni comprende tantas personas, pero existe y es de importancia. El sufrimiento, la angustia de alma y de cuerpo y la desesperación de seres humanos, tienen importancia dondequiera que se encuentren.

Exceptuando las tribus nómadas de la selva, la tierra es para los indígenas la fuente y el sostén de la vida, la compañera fiel que devuelve con sus frutos la labor paciente y cariñosa de los humildes que la labran. Sin tierra, están perdidos porque dejan de ser independientes. Al perder la tierra, tienen que trabajar para otros, alejarse del suelo nativo, en busca de otra tierra que sirva, o engrosar las masas anónimas de pueblo o ciudad; y tienen que someterse al mandato de otros. Por eso, la tierra, la parcela de tierra que labran, por pequeña que sea, es de sumo valor y de suma importancia. De ahí, su apego a la tierra; su aniquilamiento espiritual, cuando la pierden. La tierra es para ellos la vida y la independencia.

Así lo han sentido cuatro novelistas colombianos, en obras publicadas durante los últimos diez años. En sus novelas han presentado cuatro aspectos del problema del indígena y la tierra. Sin em- 
bargo, en ellas falta el aspecto que Ciro Alegría trató tan bien en El mundo es ancho y ajeno, que narra la lucha de una comunidad indígena del Perú contra el blanco que quiere adueñarse de sus tierras. Tal novela podría escribirse también en Colombia porque existen los documentos en que basarla.

Vamos a considerar.ahora las cuatro novelas colombianas, ordenadas de acuerdo con su fecha de publicación. Se comentarán dejando aparte casi todo lo que no se refiera al problema de la tierra.

José Tombé (1942), ${ }^{1}$ de Diego Castrillón Arboleda, es la historia de una comunidad de indígenas, no muy lejos de Popayán, en el oeste del país. La novela cuenta cómo fueron expulsados legalmente de tierras que labraban hacía generaciones, y la venganza fracasada que tomaron contra sus opresores.

Pedro Calapsú no puede pagar a don Hilario, terrateniente, el dinero que le debe, y para no perder su rancho tiene que consentir en casar a su hija Chola con don Hilario. Ella es novia de Claudio Tombé. Conocida la decisión de Pedro, los jóvenes deciden escaparse a vivir en el páramo; pero Claudio muere de un machetazo, en lucha con Hilario. Chola y Pedro desaparecen. Casi veinte años después, José Tombé, hijo de Claudio y Chola, comienza a organizar a los indígenas ya numerosos que han venido a vivir al páramo. Bajan en bandas al valle fértil, donde destruyen cosechas y dependencias de los blancos ricos. Después que uno del grupo delata a la comunidad, antes desconocida para las autoridades, éstas mandan tropas contra ellos. José logra unas victorias iniciales; pero la fortuna se vuelve contraria y sufre derrota tras derrota. En una correría final, contra el pueblo mismo, los indígenas resultan dispersados, muertos o presos. José, que ha subido al campanario tras Hilario para matarlo, se da cuenta de la inutilidad de la resistencia y se precipita sobre las piedras.

Tal es la sencilla trama de esta novela folklórica. Acertó Antonio García al escribir, "... Castrillón ha elaborado su novela con las indagaciones hechas en la colonización de Moscopán. La forma literaria, lejos de haber sido un recurso para evadir el análisis, se ha convertido en el modo de hacer más universal y humana la observación científica." ${ }^{2} \mathrm{El}$ autor hace sentir al lector la tremenda tragedia de estos indígenas que tienen que someterse a la voluntad, avara de riqueza y poder y exenta de piedad, de los ricos. El dile- 
ma de Pedro Calapsú servirá para mostrar hasta qué punto llegan las cosas. ¿Casar a la Chola con don Hilario o verse expulsado de su. rancho?

¿Por doce pesos que le debía lo iba a dejar en la miseria...? Le quiso suplicar que lo esperara hasta la cosecha, mas Hilario no le contestó y se alejó silbando por la falda como era su costumbre...

Así se deshizo de todos los arrendatarios que tenía en sus tierras. - Es pa hacer potrero...- decía en el pueblo.

En tres años que pasaron desde que las compró, había arrojado a casi todos los familiares indios que vivían allí. Primero los obligó a pagar por una miseria de arriendo tres días de trabajo a la semana; después, con muy buenas maneras, los llevaba a la tienda que tenía en el pueblo, situada en la esquina de la plaza, brindábales aguardiente y chicha, les ofrecía sus artículos y víveres al fiado, y cuando llegaba la cosecha, los urgía por la paga para tener el pretexto de expulsarlos y quedarse con las sementeras pagándose el doble de la deuda. ${ }^{3}$

Obrando así, dentro de la ley, don Hilario se enriquecía con la miseria y la desesperación de los indígenas indefensos. Expulsados éstos, desaparecían de la vecindad, yéndose al páramo de Moscopán donde construian casas y limpiaban y sembraban campos para establecer una colonización comunal a la manera indígena tradicional. Allí podréan vivir independientes $\mathrm{y}$, aunque con escasez, con dignidad.

Para muchos lectores, las páginas sobre la vida comunal serán lo más interesante de la novela. El autor logra interpretar el espíritu de comunidad en las tareas, fịestas y dolores, de que participan todos. Son una prueba de que el autor está convencido de lo bueno del carácter indígena. A pesar de las riñas y borracheras, la vida de la colonización es casi idílica. Unidos los de Moscopán por sus labores, gozos y sufrimientos comunes, nace entre ellos un espíritu de solidaridad que los une a todos. Por eso José Tombé, alimentado. por su madre con odio a los blancos ricos, puede reunirlos en banda. José les dice que deben posesionarse otra vez de las tierras que antes eran suyas. Les infunde odio, rebeldía y el deseo de vengan$\mathrm{za}$, hasta que le siguen al valle en las depredaciones. Con la mente cargada de injusticias sufridas a manos de los blancos y con el corazón lleno del deséo de vengarse del trato despiadado de los ricos, 
los indigenas avanzan resueltos, aunque ya antes de comenzar no estaban en posibilidad de salir con éxito.

Precisamente en eso estriba la tragedia de la novela. Ya antes de comenzar sus actos de rebeldía, no existía para ellos la posibilidad de éxito. Claro está que nunca se puede rectificar un mal con otro. Así es y así debe y ha de ser. Las autoridades tenían que poner fin a los actos ilegales de los indígenas; pero no había para éstos manera de obtener justicia. Los blancos ricos obraban sin justicia, pero dentro de la ley y apoyados por la ley; y los que sufrían tenían que callar y resignarse. $Y$ si no, ila muerte! Llegaron por fin a preferir la muerte.

A juzgar por el estilo, en muchas partes parece que Castrillón Arboleda estaba inflúdo por escritores indigenistas ecuatorianos. Al leer José Tombé el lector se fija primero en el diálogo, en dialecto muy indio. La novela hace pensar en Huasipungo, de Jorge Icaza, por su amargura y su grito apasionado de violenta protesta. Pero José Tombé no consiste sólo en diatribas contra blancos ricos y sus secuaces. Está suavizada con toques idilicos de la vida comunal de los indígenas, con escenas de costumbrismo escritas con comprensión y con aprecio de la sencillez de su manera de vivir. Para el lector, José Tombé es más amena y menos angustiadora que Huasipungo. Sin los excesos tan característicos de los indigenistas ecuatorianos, Castrillón presenta muy sólidamente la tragedia de los indigenas que pierden la tierra por la injusticia legal de los que obran dentro de la ley.

Cada voz lleva su angustia (1944), ${ }^{4}$ de Jaime Ibáñez, trata de una agrupación de ranchos indígenas, a media hora de paseo en automóvil, al norte de Bogotá. Contrasta marcadamente con la novela anterior. Mientras José Tombé está escrita en un tono directo, duro y vigoroso, Cada voz lleva su angustia rechaza la tentación de reflejar el habla de los campesinos. El autor dice: "Se observará en los diálogos el uso de palabras comunes desprovistas de la desfiguración con que hablan nuestros campesinos. Hubiera podido hacerlo en otra forma deteniéndome estérilmente en lo superficial. Pero he preferido hacerlo así como reacción a la literatura vernácula que funda todo su poder en los dialectos y modismos del pueblo." 5 Tenemos aquí, pues, una obra de intención conscientemente artística $y$ de plan bien madurado. 
También contrasta marcadamente con la novela anterior, la manera cómo los indígenás pierden la tierra. En José Tombé la pérdida es una expulsión legal efectuada por los terratenientes. En Cada voz, la pérdida ocurre al ponerse estéril la tierra. Ante la pérdida de la tierra, resultado de fuerzas combatibles, José Tombé y sus hombres se insurreccionan. Pero en Cada voz las fuerzas son incombatibles y los indígenas no pueden aliviar la angustia de espíritu que tienen. Tienen que sufrir, callar y soportar lo que urda la suerte. Del sufrimiento y del silencio forzado, surgen reacciones psicológicas muy variadas, según el individuo. El desarrollo de estas reacciones forma la sustancia de la novela.

Isidro, hijo de madre indígena y padre blanco desconocido, se queda en el rancho en que nació. Pero ve claro las cosas y aconseja a Jacob, su hermano menor, y a María, prima de ellos, que se vayan del rancho, cultivado por Jacob. Débil por falta de alimentos en su parcela estéril, aunque ayudado por Jacob y el vecino Ferro, Isidro no puede sanar de una úlcera en la pierna que a la larga es la causa principal de su muerte.

Jacob, joven de veintidós años, tiene un amor entrañable a la tierra. Luchan en él ese amor a la tierra y la insistencia de María en que se quede, contra el consejo de Isidro y el amor a Teresa, que piensa partir con su hermano, para tierras donde "dizque" hay tierra buena y aprovechable. Al fin Cob se va dejando a María en casa de Ferro.

Ferro, el vecino generoso, cariñoso y paciente, ayuda a todos. Le amarga la vida un hijo, Nicolás, que tuvo de una esposa blanca, en la capital. El muchacho sale a la madre y no puede soportar ld. vida del campo. Lleno de odio a Isidro, cuando éste defiende a María contra un ataque del chico, Nicolás pone fuego a la choza en que Isidro está dormido. Luego, en la oscuridad de la noche, huyendo con miedo por la muerte del viejo, el muchacho cae en una barranca y muere desnucado. Ferro sigue ayudando a todos los amigos. Ha jurado morir, echándose sobre un rastrillo cuando su tierra se ponga estéril, porque no quiere vivir dependiendo de otros. Al final, cuando ocurre lo inevitable y la tierra de Ferro ya no sirve para nada, María está a su lado.

María, la joven dulce, callada y sufrida, resiste con resolución a la necesidad de irse de su rancho. Persuade a Jacob de que el 
joven se quede un poco más. Ella sufre al ver que Cob no la quiere y que puede dejarla por Teresa. Sin embargo, sigue prodigando a Cob todas las atenciones de que su amor de virgen es capaz, y muestra casi la misma solicitud para Isidro, Ferro y hasta Nicolás. Cuando no quedan más que ella y Ferro, ella se busca también un rastrillo y espera con él la muerte de la tierra, la cual no tarda mucho en llegar. El autor nos deja suponer que los rastrillos son eficaces.

Así desaparece por completo esta agrupación de indígenas. Algunos mueren de vejez; Isidro muere indirectamente por su debilidad física causada por la insuficiencia de alimentos; otros se van a las fincas de la sabana de Bogotá, donde se ganan la vida trabajando en tierras ajenas; y otros llegan a la ciudad, donde se integran a las masas anónimas de pobres. $\mathrm{Y}$ los' demás, muy pocos, no pudiendo dejar por completo la tierra, se marchan hacia regiones desconocidas, en busca de tierra nueva de la que han oído decir que pueden posesionarse.

El libro entero está lleno de hondas y sentidas interpretaciones del espiritu del alma de los indigenas. El autor siente las ideas y emociones de ellos, con una ternura y penetración sorprendentes, y las transcribe a la página con comprensión. Es posible que de cuando en cuando refleje verdades universales y no las estrictamente indigenas.

El apego a la tierra, el lazo invisible que liga a los indígenas al suelo nativo, se expresa en Cada voz, por medio del animismo. El autor no usa demasiado este recurso artístico, y logra por eso realzar lo poético de la obra. A continuación viene la escena en que la Tierra habla a Jacob, quien anda con una carga de leña en la espalda, esperando venderla en el pueblo. Arriba está el rancho seco y amarillento, de tierra muerta; abajo se despliega la sabana verde, de vegetación abundante.

Cob suspiró:

- "Si tuviera esto, - pensó- lo que ahora puedo tapar con la uña de mi dedo pequeño ... la mitad, la mitad de la mitad... de esta tierra. ¡ $\mathrm{Ah}$ ! ¡ Cuánto daría yo, cuánto !".

- "i.Me cambiarías asi, Cob?..." - dijo la tierra desde lo alto de las colinas. Era una voz seca, polvorienta, como la que puede producir un violín después de largo abandono. Una lenta voz, dulcísima, en lo profundo de su mustia agonía. 
- "Cob, Jacob... Por un pequeño pedaso de otra tierra ¡... Tú, mi amado, me cambiarías sin vacilar... Oye Jacob! Todos los siglos sostuve tu sangre. Tú no lo sabes, criatura; miles, miles de años... Qué hubiera sido de ti, de tui raza, si cuando destruyeron th pueblo otras gentes poderosas, no hubiese tenido tu sangre este miserable regazo mio, estas colinas que hoy quieres abandonar. Cob, criatura, mi pequeño Jacob..."

Era un viento blando como una caricia.

Cob continuó descendiendo. ${ }^{6}$

Así se manifiesta una forma del apego a la tierra. Cob nunca supo si fué la tierra la que le había hablado o si él mismo intuía y sentía lo de miles y miles de años y lo del regazo que abrigó a sus antepasados. Sólo sabía que era dificilísimo para él dejar el suelo nativo, aunque quedarse era morir lentamente, porque la tierra ya había muerto.

El problema del indígena y la tierra, surge en otra forma en un episodio de Chambú (1946), ${ }^{\top}$ de Guillermo Edmundo Chaves. En los alrededores de Pasto, en el sudoeste del país, hay veintiuna comunidades de indígenas. De ellos dice el autor:

Su demasiada bondad era pasividad tan sólo; su sumisión no era sino obligada aceptación de vasallaje; su tristeza era el dolor no dicho ante la imposición altanera de los blancos. No es que se los ultrajara de obra o se los vilipendiara, pero sí se los condenaba por cálculo o por costumbre a recibir precios misérrimos por su trabajo. Nada se les había quitado tampoco, ni los despojaba o perseguía; pero se los obligaba a mantenerse en veredas estrechas, a vivir como pupilos de mísera manera, a no tener una mística de amor para la vida. Su concepción del gobierno era de temor. $\mathrm{Y}$ quizá de aquella guisa era el sentido de su moral. Había injusticia pues. No la que clama venganza, pero sí la que pide una reforma comprensiva y una orientación más humana. 8

Luego sigue el episodio que nos interesa.

Un grupo de indígenas jóvenes, capitaneados por Mateo Cuaipe, acuden a Ernesto, blanco al que respetan y en quien confían. Por el número, siempre en aumento, de indígenas en la comunidad, ya no hay tierra suficiente para sostener a todos. Piden ayuda a Ernesto y tratan de conseguir título para más tierra. Este comienza a estudiar títulos, para guiarlos convenientemente. En esto se entera del asunto Antonio, otro blanco. Ve una mina aprovechable en los 
jóvenes excitables y resuelve explotarlos. Mediante grandes sumas por su ayuda, les aconseja posesionarse de tierras de dueño conocido. "La tierra es de quien la cultiva y de nadie más." Los jóvenes siguen los consejos de Antonio y entran en tierras privadas. Las autoridades, reconociendo el problema y la buena voluntad de los indígenas, no quieren obrar con demasiada firmeza. Siguen los abusos hasta que el gobierno tiene que proceder con decisión. Los jóvenes asaltan una escolta mandada contra ellos para resguardar las fincas invadidas. Antonio comienza a temer lo que pueda suceder y decide perder al grupo. Les indica que opongan una resistencia total a la autoridad. Asaltan otra vez a los policías, pero Mateo decide retirarse, para que los suyos no sufran bajas. Al huír, Mateo recibe una bala en la pierna. En el hospital no quiere que le amputen la pierna ya gangrenosa. Antes de morir, se lo dice todo a su padre, que luego mata a Antonio en una pelea de hombre contra hombre.

He aquí la tragedia. Una comunidad de indígenas, que forman una parte valiosa de la vida social y económica de la región y que por eso están en aumento, necesita más tierra; pero, como dice el autor, "Su concepción del gobierno era de temor." $Y$ acuden a Ernesto, blanco a quien pueden fiarse, en vez de formular su petición ante las autoridades. Porque no comprendían lo que tenía que suceder a consecuencia de sus incursiones en tierras particulares, cayeron presa de los falsos consejos de Antonio. Se dejaron llevar por un mal camino, y se encontraron desafiando la ley. ¿Hay alguna solución? $\mathrm{El}$ autor indica una, "una reforma comprensiva $\mathrm{y}$ una orientación más humana" para que el indígena no tema al gobierno y para que éste prevea las necesidades futuras, antes que se efectúen incidentes como el del episodio discutido.

Andágueda (1946 ó 1947), ${ }^{9}$ de Jesús Botero Restrepo, es la última de las cuatro novelas. Es el rẹlato de la evolución de un rincón del sudeste del Choco, aquel departamento largo y estrecho, situado entre los Andes y el Pacífico. Esta parte de Colombia fué una de las ủltimas que perdieron su carácter agreste. La mano "civilizadora" de los blancos obró lentamente allí, cambiando, domando y transformando el mundo de la naturaleza. Donde antes había selva y más selva, con habitantes indigenas y unos cuantos bogas y mineros, regidos por la ley del más fuerte, la ley de la hombría, se 
encuentran ahora sólo pedazos de selva, unos cuantos indígenas y muchos blancos, muchos negros y la ley del blanco.

Andágueda es también un relato que trata de Honorio Ruiz, blanco o mestizo fuerte, pero sin mucha educación formal. No le gusta luchar por la vida en la ciudad, donde se pierde el contrincante, emboscándose tras una cara sonriente e hiriendo mortalmente armado con sutilezas legales. Ruiz prefiere el trato franco y abierto con amigo o enemigo; prefiere una vida sencilla aunque dura y peligrosa. Por eso se va a vivir a la selva. Al avanzar la ola de la civilización que amenaza con ahogarlo, sigue "monte adentro y más adentro".

$Y$ finalmente, Andágueda es el relato de la "rotación al abismo", de un grupo de indígenas. Para no vivir a solas en la selva, Ruiz busca la agrupación de indigenas de Manuel Querágama. Sin pedirle permiso, les dice que ha venido a vivir con ellos. Se casa a la india con la hija de Manuel, Clara Rosa, a quien ya conoce y ama a su modo. Se integra Ruiz a la vida india, trabajando y holgando, emborrachándose, alegrándose y entristeciéndose con los demás.

Borracho una noche, como en una visión Ruiz comprende que los indígenas de este rincón del país no sirven para nada y que sólo esperan, penando lo menos posible, la llegada de la muerte. Pocos días después, Ruiz trata de hacer comprenđer al grupo que dentro de algunos años no quedará selva a que retirarse, ante la presión de la civilización que avanza irresistiblemente, pero el plazo que indica, siete $\mathfrak{u}$ ocho años, es demasiado largo para que comprendan y no le hacen caso. Luego llega un blanco, con palabras engañosas y con dinero para comprar las casas y las tierras limpiadas y sembradas con tanto trabajo. El blanco habla de baldíos e indica que ofrece pagarles unos cuantos pesos, sólo por benevolencia y que si rechazan su oferta, quedarán sin casas, campos ni dinero. Ruiz no puede hacerles comprender que sus tierras ya no son baldías y que pueden quedarse en ellas con toda seguridad; pues los indígenas le tienen miedo a la ley del blanco porque no la comprenden y, por lo tanto, es un misterio y una amenaza para ellos. Deciden vender y retirarse otra vez monte adentro. Como dice Donato Tunay: "-Mejor vendiendo era. Cuando racional mucho queriendo una cosa, verdaderamente llevó sin plata lueguito. -Umjí. Eso bien dicho era - convinieron todos." $10 \mathrm{Y}$ vendieron. 
¿Qué fué del grupo? Algunos se quedaron a trabajar para los nuevos dueños. Otros, como Donato Tunay, prefirieron quedarse para esperar la muerte en un recodo de la selva. Los dèmás se fueron selva adentro, a limpiar, sembrar y construir de nuevo. $Y$ esta vez las treinta familias del grupo de Manuel Querágama se vieron reducidas a cinco.

Cuando nace un hijo de Ruiz, éste se da cuenta de lo que será de su hijo Manuel, criado en el seno de una comunidad indígena. Para evitarle el vástago penas futuras, Ruiz decide volverse rico. Hace recoger oro a los del grupo y da en dominarlos por completo. Pasa algún tiempo en que los campos andan descuidados por el afán al oro. Se descubre un aluvión rico, río abajo, y Ruiz obliga a los indígenas a que abandonen el caserío y se muden de sitio. Ya no tienen tiempo para campos nuevos. Con una parte del oro recogido, compran los víveres; pero llegan las lluvias torrenciales que se llevan chozas, árboles y el rico aluvión: lluvias que continúan semana tras semana, hasta que no le queda al grupo casi nada que comer. Lo malo es que Ruiz los ha abandonado, dejándolos sin voluntad, sin decisión, sin nada. Infieles a la tradición multi-secular de la raza, por haber dejado el cultivo, están perdidos. Ahora sí son una raza "infructuosa, en rotación al abismo." Poco a poco el grupo desaparece desintegrándose lentamente. Juan Bucamá se va acompañado de Clara Rosa y de su hijo Manuel Ruiz. Se va diciendo "Indio haber algo en Pasagra arriba, todavía. Allá vivir tal vez." ${ }^{2}$ Y el autor añade luego: "En ese tal vez estaba sintetizada toda la tremenda tragedia india." 13

Escrita probablemente en 1946, la novela concluye con dos capítulos que presentan la región en 1950. Para entonces, ya está transformada. El blanco está en todas partes, con su civilización. Quedan sólo unos pedazos de selva y en ellos sigue viviendo Honorio Ruiz, fiel a su decisión de hace años, de vivir en la selva y fiarse a su hombría. Se ha hecho una figura legendaria para toda la región; hasta tal punto, que Manuel Ruiz, criado entre blancos sin saber quién es su padre, habla del legendario Honorio, con admiración por lo raro de ese gusto de vivir en los pedazos de selva, vida para Manuel del todo incomprensible.

La pérdida de la tierra, en esta novela, por un proceso largo y continuo, es tan angustiadora para los indígenas como en las no- 
velas ya comentadas. Otra vez todo está dentro de la ley. Los blancos siguen convirtiendo la región agreste en una región que corresponda a su manera de vivir. No cabe la selva. También los indigenas de Andágueda tienen miedo a la ley del blanco y dejan de conseguir título para la tierra que han limpiado con tanto trabajo. Viene el blanco, con palabras engañosas y amenazadoras of reciéndoles unos pesos. Ayudado por el miedo del grupo, los despoja legalmente de su tierra. Ruiz trataba de explicarles que pueden y deben quedarse, pero "se convenció al cabo de que era inútil resistirse, porque la ineluctable ley del destino era la que estaba en marcha.

"Cien pesos fué el precio fijado nominalmente a las treinta chozas indígenas dispersas en este pedazo de selva. $O$, lo que es casi lo mismo, a la existencia solidaria de esta pequeña agrupación aborígen que resistió embates de siglos plantada en su sitio.

"Porque luego se dispersó como ceniza al viento." 14

Podemos preguntar por qué terminó la resistencia de Ruiz. Fué porque sólo unos cuantos días antes había tenido la visión de que sus compañeros estaban esperando, penando lo menos posible, la llegada de la muerte. Vendieron y llegó la dispersión.

$\mathrm{El}$ autor dice que los indígenas eran "una raza infructuosa, en rotación al abismo". Son palabras duras y crueles, pero también son acertadas en cuanto a este grupo. Dejan el cultivo por el oro, olvidados de la tradición de su raza. Son ahora un pueblo formado para una manera de vivir que adopta otra manera para la cual no está preparado, e infructuoso ya, sigue rodando cada vez más veloz al abismo.

Tal vez se insista aquí demasiado en eso de ser infructuosos estos indígenas. Se sabe que lo infructuoso, lo estéril desaparece del mundo del hombre, así como del mundo de la naturaleza. La agrupación de Manuel Querágama llegó a la esterilidad cuando dejó los campos, por los aluviones auríferos. En cambio, los indígenas de Chambú, en las parcialidades de Pasto, tenían un lugar importante en la vida social y económica de la región. Producían más de lo que consumían. Lejos de desaparecer, estaban en aumento. Los problemas de los dos libros son opuestos. Pero hay en ellos, como en José Tombé, un elemento común: el miedo a la ley del blanco, 
ley que no comprendian los indígenas y ley que obra siempre a favor del blanco porque sólo él sabe sacar ventaja de ella. En el fondo, la tragedia viene de esta ley. Lo trágico es que la ley fué escrita con idealismo para darles igualdad a todos.

¿Hay solución al problema? Sí la hay. Lo citado de Chambú indica el rumbo que habrá de tomar, "una reforma comprensiva y una orientación más humana." ¿Vale la pena conservar a los indígenas? Sí vale, en los más de los casos, aunque no en todos porque hay indigenas buenos y malos, como entre los blancos. Son muy trabajadores, fuertes, sufridos y leales, para enumerar sólo unos cuantos de sus rasgos buenos. La patria necesita de ellos.

Hay otra cuestión de importancia. ¿Cuál es mejor para la patria, una población de blancos, de negros, de indígenas, con los de cada grupo separados de los demás, o una población homogénea, con los varios elementos étnicos fundidos en una masa común? Diría que la segunda. Con ricos y pobres, con varios partidos políticos, ya son bastante numerosas las divisiones internas que debilitan a un país, sin esforzarse para mantener divisiones étnicas por una caridad mal encaminada. Por eso, si los grupos indígenas en las diversas regiones del país desaparecen, integrándose a la población general, la patria no sufre pérdidas irremediables. Es que el proceso de homogeneización está efectuándose. Entretanto, mientras este proceso avanza hacia la meta deseada, es necesario seguir protegiendo a los indígenas, a fin de que no se vean exterminados por su falta de capacidad para adaptarse a la nueva manera de vivir que amenace con ahogarlos. El camino de la reforma comprensiva y la orientación más humana ha de trazarse con cuidado y con justicia. No deben desesperanzarse los gobernantes ni mucho menos los gobernados, para quienes se trace el camino, si tarda mucho tal programa de reforma en brindar sus frutos a la patria. Lo bueno, sea lo que sea, siempre cuesta mucho trabajo, energía y fe, antes de que se consiga.

Jean P. Keller, University of Washington, Seattle, Washington. 


\section{NOTA S}

1 Castrillón Arboleda, Diego, José Tombé. Bogotá, Edit, Antena, 1942. $183 \mathrm{p}$.

2 García, Antonio, "E1 indigenismo en Colombia, génesis y evolución", en "América indígena". Vol. v, No 3, julio de 1945, p. 231.

3 Op. cit., p. 18.

4 Ibáñez, Jaime, Cada voz lleva su angustia. Bogotá, Edit. Santafé, 1944,340 p.

5 Op. cit., p. 8.

6 Op. cit., pp. 50-51.

7 Chaves, Guillermo Edmundo, Chambí. Manizales, Impr. Oficial, 1946. $387 \mathrm{p}$.

8 Op. cit., D. 192.

9 Botero Restrepo, Jesús, Andágueda. Bogotá, Edit. A B C, 1946 ó 1947, $208 \mathrm{p}$.

10 Op. cit., pp. 96-97.

11 Op. cit., p. 110.

12 Op. cit., p. 165.

13 Op. cit., pp. 165-166.

14 Op. cit., p. 97. 
